\title{
Recobrimentos nanoestruturados a base de ácido hialurônico e quitosana com propriedades controladas para fins de interesse biomédico
}

\author{
Giulia G. Lima*, João B. M. R. Neto, Marisa M. Beppu.
}

\section{Resumo}

Uma das grandes preocupações no desenvolvimento de biomateriais é o alto potencial que organismos patogênicos têm de aderir-se nas superfícies, visto que infecções causadas por fungos e bactérias ainda contabilizam milhões de mortes por ano. Neste contexto, a técnica de Layer-by-layer mostra-se uma interessante estratégia para a produção de recobrimentos com potencial biomédico, exibindo, por exemplo, propriedades antimicrobianas e/ou de adesão de células tumorais. Aqui, foram produzidos recobrimentos a base de ácido hialurônico (HA) e quitosana (CHI) com propriedades controladas a fim de investigar a influência de condições de preparo dos filmes no potencial antimicrobiano destes.

\section{Palavras-chave:}

Layer by layer, quitosana, atividade antimicrobiana.

\section{Introdução}

Estudos realizados anteriormente sugerem que a quitosana e seus derivados têm a propriedade de ligarse a membranas celulares de micróbios e destruir seu material genético, impedindo sua proliferação. De modo a explorar esse potencial, foram produzidos filmes multicamadas de HA/CHI. Neste trabalho, avaliou-se como o grau de acetilação da quitosana e o $\mathrm{pH}$ das soluções poliméricas influenciam nas propriedades físico-químicas dos recobrimentos e no seu potencial antimicrobiano. Em suma, foram produzidos filmes contendo 20 bicamadas via Layerby-layer dipping coating nas condições de $\mathrm{pH} 4,5 \mathrm{e}$ $\mathrm{pH} 7,0$, utilizando-se quitosanas com diferentes graus de acetilação 15,35 e $60 \%$. Após a produção dos recobrimentos, estes foram caracterizados através das técnicas de Perfilometria, Microscopia de Força Atômica e Espectroscopia de UV-Visível.

\section{Resultados e Discussão}

A Figura 1a apresenta os resultados de espessura média dos filmes via Perfilometria. Sugere-se que a espessura dos filmes está diretamente ligada à conformação das moléculas poliméricas em solução. Em pH 4,5, ambos os polieletrólitos apresentam alta disponibilidade de cargas e conformação linear em solução. Já em pH 7, o ácido hialurônico continua altamente ionizado sob conformação linear, enquanto a quitosana apresenta uma baixa densidade de cargas, assumindo uma conformação de caráter enovelado. Desta forma, há uma quantidade menor de cargas positivas disponíveis na CHI para interagir com as cargas negativas do HA em pH 7.0, sendo necessárias mais moléculas de quitosana para interagir com o ácido hialurônico de modo que haja o fenômeno de compensação de cargas e formação das multicamadas. Por este motivo, filmes produzidas em $\mathrm{pH} 7.0$ apresentam maior espessura quando comparados com os recobrimentos preparados em $\mathrm{pH}$ 4.5. A Figura $1 \mathrm{~b}$ apresenta os resultados de absorbância via UV-Vis dos recobrimentos, que foram tingidos com o corante rosa de bengala $(\mathrm{RB})$. O RB interage diretamente com os grupos amino livres da quitosana, que, teoricamente, são os responsáveis pela atividade antimicrobiana. Novamente, esses resultados são consequência do grau de ionização dos polieletrólitos. O baixo grau de ionização da $\mathrm{CHI}$ em pH 7, faz com que haja mais grupos amino livres para interagir com o corante, levando a valores de absorbância notavelmente maiores nesta condição em relação ao $\mathrm{pH}$ 4,5. Em relação ao potencial antimicrobiano, sugere-se que é possível aumentar a resistência à $E$. coli através de um efeito combinado de maior disponibilidade de grupos amino e menor rugosidade da superfície dos recobrimentos (ver resultados de AFM e antimicrobiano no relatório final e pôster).

Figura 1. (a) Medidas de espessura e (b) Absorbância do corante rosa de bengala para filmes de (HA/CHIx)y, onde $\mathrm{x}$ indica o grau de acetilação da quitosana e y o pH dos filmes.

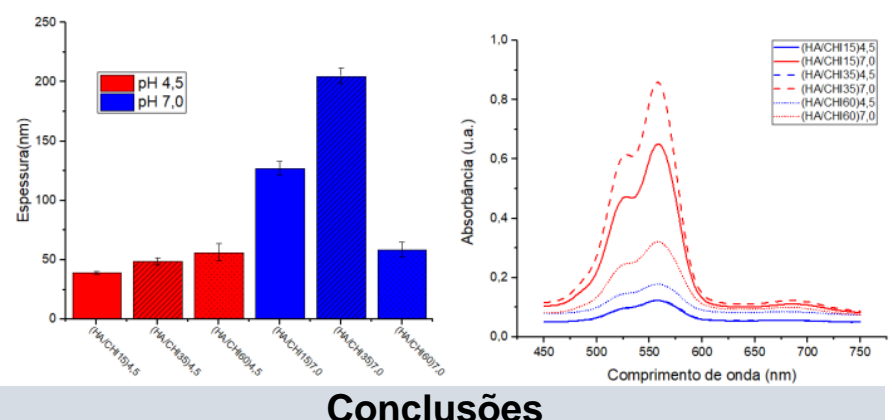

O ajuste de parâmetros simples de formação como grau de acetilação e pH são capazes de modular as propriedades físico-químicas e o potencial antimicrobiano de recobrimentos a base de $\mathrm{CHI}$ e HÁ.

Agradecimentos

Lequip, LNNano e CNPQ. 